\title{
Cyber victimization and adjustment difficulties: The mediation of Chinese and American adolescents' digital technology usage
}

\author{
Michelle F. Wright \\ Masaryk University, Brno, The Czech Republic
}

\begin{abstract}
Researchers have focused on identifying factors which might reduce the negative consequences associated with cyber victimization. One prominent factor receiving attention is the role of parental mediation in adolescents' digital technology usage, and how such mediation reduces the risk of cyber victimization. Less attention has focused on different mitigating agents (i.e., teachers, friends) and their influence on adolescents' cyber victimization. Another area that has received little attention is the buffering effects of different mitigating agents on the psychosocial adjustment difficulties (i.e., depression, loneliness, anxiety) associated with cyber victimization. To address this gap in the literature, the present study investigated the role of different mitigating agents (i.e., parents, teachers, friends) in buffering against the psychosocial adjustment difficulties associated with cyber victimization among 483 Chinese (49\% female) and 467 American (52\% female) adolescents in the eighth grade (ages ranging from 13-15). Findings revealed that all adolescents experienced more mediation by their parents, with Chinese adolescents reporting more parental mediation when compared to American adolescents. Chinese adolescents also reported more teacher mediation, while American adolescents experienced more friend mediation. In addition, high levels of parental mediation made the relationship of cyber victimization to depression and anxiety more negative for both Chinese and American adolescents. The relationships of cyber victimization to depression and anxiety were moderated by teacher mediation for Chinese adolescents, whereas this pattern was not found for American adolescents. On the other hand, friend mediation moderated the relationship of cyber victimization to depression and anxiety for American adolescents, but not for Chinese adolescents. The results of this study are discussed in terms of cultural values and how such values alter the role of adults and friends in adolescents' lives.
\end{abstract}

Keywords: cyber victimization, mediation, depression, anxiety, loneliness

\section{Introduction}

Digital technology usage has grown exponentially over the last few decades. Such technology usage has become instrumental to many of our daily activities, allowing us to work more efficiently, have a vast amount of information at our fingertips, and communicate quickly with other people. Many adolescents have grown up completely enmeshed in the digital world, without ever knowing a world in which technology was not integral to their daily lives. For many adolescents, technology is a major part of their lives, with many using the internet and mobile devices daily (Madden, Lenhart, Duggan, Cortesi, \& Gasser, 2013). Digital technology usage has both positive and negative consequences (Bavelier, Green, \& Dye, 2010; Lepičnik-Vodopivec \& Samec, 2012; Rosen, Whaling, Carrier, Cheever, \& Rokkum, 2013). Due to adolescents' potential exposure to the negative consequences associated with digital technology usage, researchers, parents, educators, and the general public have expressed interest in understanding 
strategies which might reduce or mitigate these consequences. Parental supervision is one factor proposed to protect against the negative consequences associated with adolescents' digital technology usage (Abelman, 2006; Nikken \& Jansz, 2006). Research reveals that a lack of parental supervision relates to cyberbullying and exposure to pornography (Lwin, Stanaland, \& Miyazaki, 2008; Mesch, 2009). Therefore, attention has been given to parents' mediation of adolescents' technology usage in order to understand the buffering effect it has on the negative consequences associated with technology usage.

As the literature on cyberbullying has developed, the mediation of adolescents' usage of digital technology has received attention as having a potential buffering effect against the negative consequences associated with such bullying. This is especially important as victims of cyberbullying are susceptible to an assortment of psychosocial adjustment difficulties, including depression, anxiety, and loneliness (GámezGuadix, Orue, Smith, \& Calvete, 2013; Landstedt \& Persson, 2014; Olenik-Shemesh, Heiman, \& Eden, 2012). Despite these associated psychosocial adjustment difficulties, little attention has been given to whether the mediation of adolescents' use of digital technology helps to mitigate some of the difficulties associated with cyber victimization. The most commonly identified mitigating agents in the literature are parents. Although teachers are increasingly incorporating digital technologies within their classrooms, potentially creating opportunities to discuss appropriate technology usage, little attention has been given to whether this potential for support actually occurs (Blackwell, Lauricelli, \& Wartella, 2014; Lee \& Thomas, 2011; Nijs \& Leman, 2014). In addition, peer relationships are incredibly important in adolescence, and adolescents' friends might also serve as mitigating agents (Parker, Rubin, Erath, Wojslawowicz, \& Buskirk, 2006). Furthermore, the importance of parents, teachers, and friends varies across countries, and, therefore, the effects of these individuals as mitigating agents might differ based on adolescents' cultural background (Edwards, Rosario de Guzman, Brown, \& Kumru, 2006).

To this end, one goal of present study was to examine cultural differences in the mediation of adolescents' digital technology usage by their parents, teachers, and friends. A secondary goal was to investigate the buffering effects of this mediation in the relationships among cyber victimization and psychosocial adjustment difficulties (i.e., depression, anxiety, loneliness), and whether cultural differences might be found for these relationships as well.

\section{Cyber Victimization and Mediation of Children's Use of Technology}

With the emergence of digital technology, cyberbullying has received increased attention from researchers, teachers/schools, parents, children/adolescents, and the general public. Cyberbullying, a new form and extension of face-to-face bullying, occurs when bullies target victims via cyberspace (Smith, Mahdavi, Carvalho, Fisher, Russell, \& Tippett, 2008). Bullies might target victims through emails, instant messaging, chat rooms, social networking sites, and text messages. Furthermore, this form of bullying aims to be intentionally humiliating, tormenting, threatening, or harassing to the victim (Grigg, 2010). Cyber victimization can occur one-on-one, among groups, or include a mass audience (Dooley, Pyzalski, \& Cross, 2009). Prevalence rates of cyber victimization vary from $6 \%$ to $41 \%$, depending on the definition of cyber victimization, the measurement of cyber victimization, the time parameters used to assess this experience (e.g., lifetime prevalence rates versus school-year prevalence), and the samples used ( $\mathrm{Li}$, 2006; Nivers \& Noret, 2010; Wright, 2014). Regardless of the variations in adolescents' reports of cyber victimization, understanding this experience is important as victims report contemplating suicide, depression, anxiety, and loneliness as well as lower academic performance, and alcohol and drug use (Bauman, Toomey, \& Walker, 2013; Campbell, Spears, Slee, Butler, \& Kift, 2012; Huang \& Choi, 2010; Kowalski \& Limber, 2013; Mitchell, Ybarra, \& Finkelhor, 2007; Schenk, Fremouw, \& Keelan, 2013).

Due to the psychosocial adjustment difficulties associated with cyber victimization, researchers have directed their attention to factors which might buffer or reduce the negative effects of experiencing cyberbullying. One such factor is the mediation of adolescents' technology usage by various agents (Livingstone \& Helsper, 2008; Van Den Eijnden, Meerkerk, Vermulst, Spijkerman, \& Engels, 2010). Though in its infancy, most of this research focuses on parental mediation and how such mediation affects adolescents' experience of cyber victimization. Parental mediation is defined as the strategies that parents use to manage the relationship between their children and media (Livingstone \& Helsper, 2008). There are various typologies of parental mediation strategies including passive, active, restrictive (i.e., setting rules), and all-round mediation (see Helsper, Kalmus, Hasebrink, Sagvari, \& De Haan, 2013 for review). In one study, Dehue, Bolman, and Völlink (2008) found that parents of primary and secondary school children reported setting rules concerning internet usage. Most of these rules concerned the frequency of usage and rules regarding what children are allowed to do on the internet. However, they did not find that parents set rules concerning internet harassment. Mesch (2009) surveyed parents concerning the mediation strategies they utilized to monitor their children's internet activities. Findings revealed that parental mediation served as a protective factor against experiencing cyber victimization, particularly 
when parents monitored and set rules about the websites their children were allowed to visit. Similar results were found by Navarro and colleagues (2013). In their study, parents' usage of monitoring software, and the joint creation of rules regarding time spent online and the appropriate sharing of personal information lessened the risk of cyber victimization among adolescents. One of the most current studies on parental mediation also indicated that adolescents who reported higher parental mediation were less likely to engage in or experience cyberbullying (Chang et al., 2014). Mascheroni, Jorge, and Farrugia (2014) suggest that "parents seem to use the media as a gateway to discuss the dangers of cyberbullying with their children" (para. 39).

Parents are not the only agents mitigating adolescents' use of digital technology. Even though research on this topic has been slow to develop, there is evidence that children and adolescents report that other people, particularly teachers and peers, are involved in their digital technology usage as well (Livingstone, Haddon, Görzig, \& Ólafsson, 2011). However, this research does not indicate whether such mediation buffers against the effects of cyber victimization. Mediation from teachers and peers is defined as the strategies used and help offered by these mitigating agents to support and influence adolescents' use of digital technology. In a large-scale survey of European children and adolescents, half reported that their teachers have engaged with the children's use of technology and almost three-quarters indicated that their teachers have actively mediated this usage, either by discussing with the children what they do online or through setting rules about the children's online activities (Livingstone et al., 2011). One quarter of these children and adolescents said that their teachers helped them when something bothered them on the internet. Because children and adolescents felt like they could go to their teachers when something bothered them online, teacher mediation could act as a buffer against the psychosocial adjustment difficulties associated with cyber victimization, especially considering the importance of social support as an effective coping strategy (Dumont \& Provost, 1999; Kim, Suh, Kim, \& Gopalan, 2012; Thorsteinsson, Ryan, \& Sveinbjornsdottir, 2013). Research consistently reveals that adolescents prefer to turn to their peers when something bothers or worries them online (Calvete, Orue, Estévez, Villardón, \& Padilla, 2010; Mishna, Cook, Gadalla, Daciuk, \& Solomon, 2010; Šléglová \& Černá, 2011). Three-quarters of children and adolescents reported that their peers have helped or supported their internet safety (Livingstone et al., 2011). In addition, peers help in technical ways when children and adolescents have difficulty finding something online, but peers are less likely to give safety or ethical advice. There are also differences regarding the amount of mediation offered by parents, teachers, and peers. In particular, parents frequently give out more advice concerning internet safety, followed by teachers and then peers.

\section{Mediation of Technology Usage in Different Contexts}

Little attention has been given to cultural differences in the mediation of adolescents' technology usage. One study reported national variations among European children and adolescents (Livingstone et al., 2011). In this study, Livingstone and colleagues found that children and adolescents from some countries, like Turkey, Ireland, and Bulgaria, reported more restrictive parental mediation than children and adolescents from Hungary and the Netherlands. There were also differences found concerning whether children and adolescents ignored parental mediation, ranging from $46 \%$ in the Czech Republic to $81 \%$ in Denmark. Teacher mediation also varies, with $97 \%$ of the sample from Norway reporting that their teachers play an active role in their internet usage versus $56 \%$ of children and adolescents from Italy reporting that their teachers did this. In addition, $86 \%$ of children and adolescents in Finland reported that their peers served as mediators of their digital technology usage when compared to $63 \%$ from France. National variations also exist concerning differences regarding who provided the most mediation concerning children's and adolescents' technology usage. For instance, in Portugal teachers gave more safety advice when compared to parents and peers. On the other hand, parents and peers gave more advice than teachers among Italian and Romanian children and adolescents, while peers gave the most advice in Germany.

Less attention has been given to comparisons between the different mitigating agents in countries outside of Europe. Research on this topic indicated that less instructive and restrictive parental mediation styles were used in Spain than in Bolivia and the Dominican Republic (Martínez de Morentin, Cortés, Medrano, \& Apodaca, 2014). However, this research did not examine the mediation of adolescents' use of digital technology by teachers and peers. Such a focus is important because the influence of adults, including parents and teachers, is different than the influence of peers in some cultures. For example, Chinese adolescents are raised with the cultural belief in filial piety, which guides them to obey their parents and elders (Ho, 1996; Yeh \& Bedford, 2004). Furthermore, peers have less of an influence on Chinese adolescents than their parents (Mordkowitz \& Ginsburg, 1987; Yao, 1985). In comparison to American parents, Chinese parents ensure that their children develop a sense of connectedness with their families, de-emphasizing affiliation with peers (Rothbaum, Morelli, Pott, \& Liu, 2000; Wang \& Leichtman, 2000). On the other hand, peer influence becomes more pronounced during adolescence in the United States, and, 
consequently, adolescents spend an increasing amount of time with their peers (Parker et al., 2006). The variation in the role of parents and peers might lead Chinese and American adolescents to perceive differences in the level of technology mediation by parents and peers. There might also be differences for teacher mediation as Chinese adolescents grow up in a culture in which respect for elders is extremely important. Considering these potential differences among Chinese and American adolescents, it might also be likely that technology mediation by parents, teachers, and peers could buffer against the effects of cyber victimization on psychosocial adjustment, and that such buffering might differ based on adolescents' country of origin.

\section{The Present Study}

Based on research regarding the different roles of parents, teachers, and peers in Chinese and American adolescents' lives, it is reasonable to expect that these individuals might mediate adolescents' technology usage differently. Therefore, the goal of this study was to examine differences in the amount of mediation Chinese and American adolescents receive from their parents, teachers, and friends. This study focused on friends as opposed to peers because friends provide a much closer relationship within which more technology mediation might occur. It was hypothesized that Chinese adolescents would report more mediation of technology from their parents, followed by teachers and then friends. Adults were expected to have a stronger role in technology mediation for Chinese adolescents due to cultural values emphasizing respect for elders (Ho, 1996; Mordkowitz \& Ginsburg, 1987; Yao, 1985; Yeh \& Bedford, 2004). Somewhat different patterns were anticipated for American adolescents such that they would receive more mediation from parents, followed by friends and then teachers. Though friends are a major source of influence during adolescence, it was anticipated that parents would still engage in more mediation than friends (Livingstone et al., 2011). However, because of the importance of peer culture in the US, friends were expected to mediate American adolescents' technology usage more than teachers.

Although some attention has been given to parental mediation and how it impacts cyber victimization, no research exists regarding whether such mediation reduces the negative effects of cyber victimization on adolescents' depression, anxiety, and loneliness. However, because parental mediation reduces the risk of cyber victimization, parents might buffer or mitigate the relationships between cyber victimization and adolescents' psychosocial adjustment difficulties (Mesch, 2009). Therefore, it was hypothesized that parents' mediation of adolescents' technology usage would moderate these relationships, indicating that higher levels of parental mediation would make the associations among cyber victimization and psychosocial adjustment difficulties weaker, whereas lower levels will make such associations stronger. These patterns were expected for both Chinese and American adolescents. It is difficult to develop hypotheses for teacher mediation and friend mediation as there is a lack of research on these topics. For this study, in light of the discussions of cultural differences, it was expected that teacher mediation would moderate the relationships between Chinese adolescents' cyber victimization and their depression, anxiety, and loneliness. On the other hand, this pattern concerning teachers was not hypothesized for American adolescents, though parents and friends were expected to moderate this relationship as well. Thus, the relationships between cyber victimization and psychosocial adjustment difficulties were expected to be weaker when Chinese adolescents' teachers and American adolescents' friends mediated adolescents' online experiences, whereas lower levels of such mediation would make the associations among cyberbullying victimization and these negative consequences much stronger.

\section{Methods}

\section{Participants}

Participants were middle-school adolescents in the 8th grade from Beijing in the People's Republic of China ( $n=483 ; 49 \%$ female; Mage $=14.01$ years $)$ and Chicago in the United States $(n=467 ; 52 \%$ female; Mage = 13.67 years). Their schools were from predominantly middle-class neighborhoods. Most of the Chinese participants were of Han ethnicity. From the United States, $73 \%$ were white, $20 \%$ were Latino/a, $5 \%$ were Black/African American, $1 \%$ were Asian, and the remaining $1 \%$ were biracial. Income data was not collected for this study.

\section{Procedures}

There were ten public schools randomly selected from a list of over three hundred public schools in the Chicago and Beijing areas. Letters were emailed to a random sample of five school principals in China and five random school principals in the United States. The letters introduced principals to the purpose of the study. Four school principals from China and three school principals from the United States expressed 
interest in having their school participate in the study. These seven schools are typical of other public schools in China and the United States. When a principal expressed an interest in the study, a face-to-face meeting was setup between the principal and the study's personnel to discuss the project in more detail. After agreeing to take part, another meeting was conducted with principals and teachers. During this meeting, the study's personnel discussed how important it was for adolescents to participate in the study and what adolescents would be asked to do if they were to participate. Classroom announcements were made to 8th grade classrooms (i.e. involving 13-15 year olds) at each of the schools. After the announcement, parental permission slips were sent home with the adolescents. The parental permission slip explained the study and discussed what adolescents would be expected to do if they were to participate. In China, 501 parental permission slips were passed out, and, of these, 483 were returned with permission and 10 were returned without permission. In the United States, 550 parental permission slips were passed out, and, of these, 470 were returned with permission and 25 were returned without permission. Three participants from the United States were not included in the study as they were absent on both days of data collection. No Chinese adolescents were absent on the days of data collection.

Data was collected from adolescents during the fall of 8th grade. At the time of data collection, adolescents provided their own assent to participate in the study. None declined to participate. Adolescents completed demographic information (i.e., gender, age, ethnicity), and measures on their selfreported face-to-face victimization, self-reported cyber victimization, mediation of technology usage, depression, anxiety, and loneliness. Trained research assistants administered measures to participants and all adolescents filled in the questionnaires independently. All participants were asked to raise their hands if they had any question during data collection. For American participants, adolescents completed the measures in English, while measures for Chinese adolescents were administered in Chinese, which used back-translation techniques.

\section{Measures}

Face-to-face victimization. Adolescents rated on a scale of 1 (not at all) to 5 (all of the time) how often they experienced face-to-face victimization (Wright, Li, \& Shi, 2014). There were twelve items for this measure and adolescents were asked to think of experiencing these behaviors within the current school year. Some sample items included "Someone gossiped about me," and "Someone called me insulting names." Cronbach's alpha was .94 for face-to-face victimization.

Cyber victimization. This measure was similar to the face-to-face victimization measure, except that the behaviors were described as occurring online or through text messages (Wright, 2014). Nine items were included in this questionnaire, and each were rated on a scale of 1 (not at all) to 5 (all of the time). Adolescents were asked to think about these experiences as occurring within the current school year. Example items included "Someone sent me a nasty message online or through text messages" and "Someone called me insulting names online or through text messages." Cronbach's alpha was acceptable $(a=.91)$ for cyber victimization.

Mediation of technology usage. There were three subscales (i.e., parent, teacher, friend) associated with this questionnaire (Arrizabalaga-Crespo, Aierbe-Barandiaran, \& Medrano-Samaniego, 2010). The following three items were used for all subscales: "My parents/teacher/friend show(s) me how to use the internet and warn(s) me about its risks," "My parents/teacher/friend tell(s) me what websites I should visit or which I shouldn't visit," and "My parents/teacher/friend explain(s) to me issues related to certain websites." Another item was used for parents (i.e., "My parents impose a timetable to surf the internet") and teachers (i.e., "My teacher talks to me about the appropriate amount of time to use the internet"). Four items were included for the parent subscale only: "My parents tell me to stop surfing the internet if I have used it for a long time," "My parents show interest in the websites that I visit," "My parents are present in the same room when I am surfing the internet," and "My parents surf the internet with me." There were fifteen items total for this questionnaire (eight items for parents; four items for teacher; three items for friend). Cronbach's alphas were .90 for parental mediation, .87 for teacher mediation, and .83 for friend mediation.

Adjustment difficulties. Depression was assessed with the Center for Epidemiological Studies Depression Scale (Radloff, 1977). This scale consists of twenty statements, which were rated on a scale of 0 (rarely or none of the time) to 3 (most or all of the time). Example items included: "I was bothered by things that usually don't bother me," and "I did not feel like eating, my appetite was poor." Anxiety was measured using the Multidimensional Anxiety Scale for Children (March, Parker, Sullivan, Stallings, \& Conners, 1997). There were thirty-nine items, each rated on a scale of 0 (never true about me) to 3 (often true about me). One example was: "I get scared when my parents go away." The twenty items from the Revised UCLA Loneliness Scale were used to assess adolescents' loneliness (Russell, 1996). 
Items were rated on a scale of 1 (never) to 4 (often) for this questionnaire. One example item was: "I feel isolated from others." Cronbach's alphas were .88 for depression, .90 for anxiety, and .90 for loneliness.

\section{Results}

Descriptive statistics were computed, including means and standard deviations for parental mediation, teacher mediation, and friend mediation (see Table 1), and correlations among all variables (see Table 2). Cyber victimization was related negatively to parental mediation, teacher mediation, and friend mediation, whereas it was associated positively with depression, anxiety, and loneliness. Parental mediation was related positively to teacher mediation and friend mediation, but it was associated negatively with depression, anxiety, and loneliness. Teacher mediation was related negatively to depression, anxiety, and loneliness. Similarly, friend mediation was associated negatively with depression and anxiety, but it was not related to loneliness. Depression was related positively to anxiety and it was associated positively with loneliness. Anxiety was related positively to loneliness.

Table 1. Means and Standard Deviations for Mediation among Chinese and American Adolescents.

\begin{tabular}{lcccc}
\hline & \multicolumn{2}{c}{ Chinese } & \multicolumn{2}{c}{ American } \\
& Male & Female & Male & Female \\
& $\boldsymbol{M}(\boldsymbol{S D})$ & $\boldsymbol{M}(\boldsymbol{S D})$ & $\boldsymbol{M}(\boldsymbol{S D})$ & $\boldsymbol{M}(\boldsymbol{S D})$ \\
\hline Parent Mediation & $3.36(.89)$ & $3.37(.99)$ & $3.16(.86)$ & $3.20(.88)$ \\
Teacher Mediation & $2.96(.79)$ & $2.99(.73)$ & $2.05(.81)$ & $2.06(.91)$ \\
Friend Mediation & $1.82(.81)$ & $1.90(.92)$ & $3.02(.84)$ & $3.05(.86)$ \\
\hline
\end{tabular}

Table 2. Correlations among All Variables in the Study.

\begin{tabular}{llllllll}
\hline & $\mathbf{1}$ & $\mathbf{2}$ & $\mathbf{3}$ & $\mathbf{4}$ & $\mathbf{5}$ & $\mathbf{6}$ & $\mathbf{7}$ \\
\hline 1. Cyber Victimization & --- & & & & & & \\
2. Parent Mediation & $-.30^{* * *}$ & --- & & & & & \\
3. Teacher Mediation & $-.23^{* * *}$ & $.33^{* * *}$ & --- & & & & \\
4. Friend Mediation & $-.18^{* *}$ & $.12^{*}$ & .04 & --- & & & \\
5. Depression & $.38^{* * *}$ & $-.36^{* * *}$ & $-.26^{* * *}$ & $-.21^{* *}$ & --- & & \\
6. Anxiety & $.24^{* * *}$ & $-.29 * * *$ & $-.20^{* *}$ & $-.14^{*}$ & $.51^{* * *}$ & --- & \\
7. Loneliness & $.10^{*}$ & $-.20^{* *}$ & $-.13^{*}$ & -.09 & $.24 * * *$ & $.30 * * *$ & --- \\
\hline
\end{tabular}

Note: ${ }^{*} p<.05 .{ }^{* *} p<.01 .{ }^{* * *} p<.001$.

The rest of the results are divided into two sections. The first set presents country of origin differences in the mediation of Chinese and American adolescents' technology usage. The second set examines hypotheses concerning the buffing effects of adolescents' technology mediation in the relationship between cyber victimization and adjustment difficulties (i.e., depression, anxiety, and loneliness).

\section{Differences in the Mediation of Adolescents' Technology Usage}

A one-way repeated-measures MANOVA was conducted with gender and country as between-subject variables and the within-subject variables as parental mediation, teacher mediation, and friend mediation. Two-way interactions were included between gender and mediation, gender and country, and country and mediation. Subsequently, a three-way interaction was included between gender, country, and mediation.

Findings revealed that mediation had significant effects (Wilks' $\Lambda=.83, F(2,936)=117.43, p<.001$ ). The two-way interactions between mediation and gender (Wilks' $\Lambda=.99, F(2,936)=.45, p=$ n.s.), and country and gender (Wilks' $\Lambda=.99, F(2,936)=.67, p=$ n.s.) were not significant. However, the two-way 
interaction between mediation and country was significant, Wilks' $\Lambda=.86, F(2,936)=83.14, p<$ .001. The three-way interaction among gender, country, and mediation was not significant (Wilks' $\Lambda=.99$, $F(2,936)=.89, p=$ n.s.). All adolescents reported more mediation of their technology use by parents than their teachers and friends. Overall, Chinese adolescents reported more mediation by their teachers than their friends, whereas American adolescents reported more mediation by their friends than their teachers. Chinese adolescents also experienced more mediation by their parents when compared to American adolescents.

\section{The Buffering Effects of Technology Mediation}

Confirmatory factor analysis was performed separately for Chinese and American adolescents to examine the measurement models. The model fit was adequate (for Chinese adolescents: $x^{2}=634.99, d f=847, p$ $=.99, C F I=96, T L I=95, R M S E A=.04, S R M R=.05$; for American adolescents: $x^{2}=586.16, d f=804$, $p=.99, C F I=.93, T L I=.92, R M S E A=.03, S R M R=.06)$. The standardized factor loadings had adequate magnitudes and significant factor loadings $(p s<.001)$. All items served as indicators for the latent variables in the structural regression model. The hypothesized associations were examined using two structural regression models, one for Chinese adolescents and the other for American adolescents. For both models, paths were specified from cyber victimization to the mediation of technology usage by parents, teacher, and friend and to depression, anxiety, and loneliness as well as from the mediation of technology usage to depression, anxiety, and loneliness. Mediation of technology usage was also included as a moderator in the relationship of cyber victimization to depression, anxiety, and loneliness. To account for the relationship between cyber victimization and face-to-face victimization, face-to-face victimization was controlled in the model by allowing it to predict cyber victimization. Both models showed that the structural model fit the data adequately (for Chinese adolescents: $X^{2}=879.36, d f=898, p=.67, C F I=$ 98, $T L I=97, R M S E A=.04, S R M R=.05$; for American adolescents: $x^{2}=913.06, d f=867, p=.13, C F I$ $=.94, T L I=.93, R M S E A=.03$, SRMR $=.06)$.

For Chinese adolescents, as hypothesized (see Figure 1), while controlling for face-to-face victimization, cyber victimization related negatively to parental mediation $(\beta=-.43, p<.001)$, teacher mediation $(\beta=-$ $.36, p<.001)$, and friend mediation $(\beta=-.14, p<.05)$. Cyber victimization was related positively to depression $(\beta=.41, p<.001)$, anxiety $(\beta=.34, p<.001)$, and loneliness $(\beta=.21, p<.01)$. In addition, parental mediation was associated negatively with depression $(\beta=-.36, p<.001)$, anxiety $(\beta=$ $-.32, p<.001)$, and loneliness $(\beta=-.13, p<.05)$. Teacher mediation was also related negatively to depression $(\beta=-.28, p<.001)$, anxiety $(\beta=-.20, p<.01)$, and Ioneliness $(\beta=-.13, p<.05)$. Friend mediation was associated negatively with depression $(\beta=-.20, p<.01)$ and anxiety $(\beta=-.14, p<.05)$, but not loneliness $(\beta=-.03, p=$ n.s.). Parental mediation and teacher mediation were significant moderators in the relationship between cyber victimization and depression as well as between cyber victimization and anxiety. Probing the interactions further revealed that higher levels of parental mediation and teacher mediation made the relationship between cyber victimization and depression more negative. On the other hand, lower levels of parental mediation and teacher mediation made the relationship between cyber victimization and depression more positive. Similar patterns were found for the relationship between cyber victimization and anxiety.

For American adolescents, cyber victimization related negatively to parental mediation $(\beta=-.37, p<$ $.001)$, teacher mediation $(\beta=-.17, p<.05)$, and friend mediation $(\beta=-.27, p<.001)$, while controlling for face-to-face victimization (see Figure 2 ). Cyber victimization was related positively to depression $(\beta=$ $.43, p<.001)$, anxiety $(\beta=.37, p<.001)$, and loneliness $(\beta=.24, p<.01)$. In addition, parental mediation was associated negatively with depression $(\beta=-.32, p<.001)$, anxiety $(\beta=-.26, p<.01)$, and loneliness $(\beta=-.11, p<.05)$. Teacher mediation was also related negatively to depression $(\beta=-.17$, $p<.01)$ and anxiety $(\beta=-.15, p<.05)$, but not loneliness $(\beta=-.05, p=$ n.s. $)$. Friend mediation was associated negatively with depression $(\beta=-.28, p<.001)$ and anxiety $(\beta=-.19, p<.001)$, but not loneliness $(\beta=-.01, p=$ n.s. $)$. Parental mediation and friend mediation were significant moderators in the relationship between cyber victimization and depression as well as between cyber victimization and anxiety. Probing the interactions further revealed that higher levels of parental mediation and friend mediation made the relationship between cyber victimization and depression more negative. On the other hand, lower levels of parental mediation and friend mediation made the relationship between cyber victimization and depression more positive. Similar patterns were found for the relationship between cyber victimization and anxiety. 


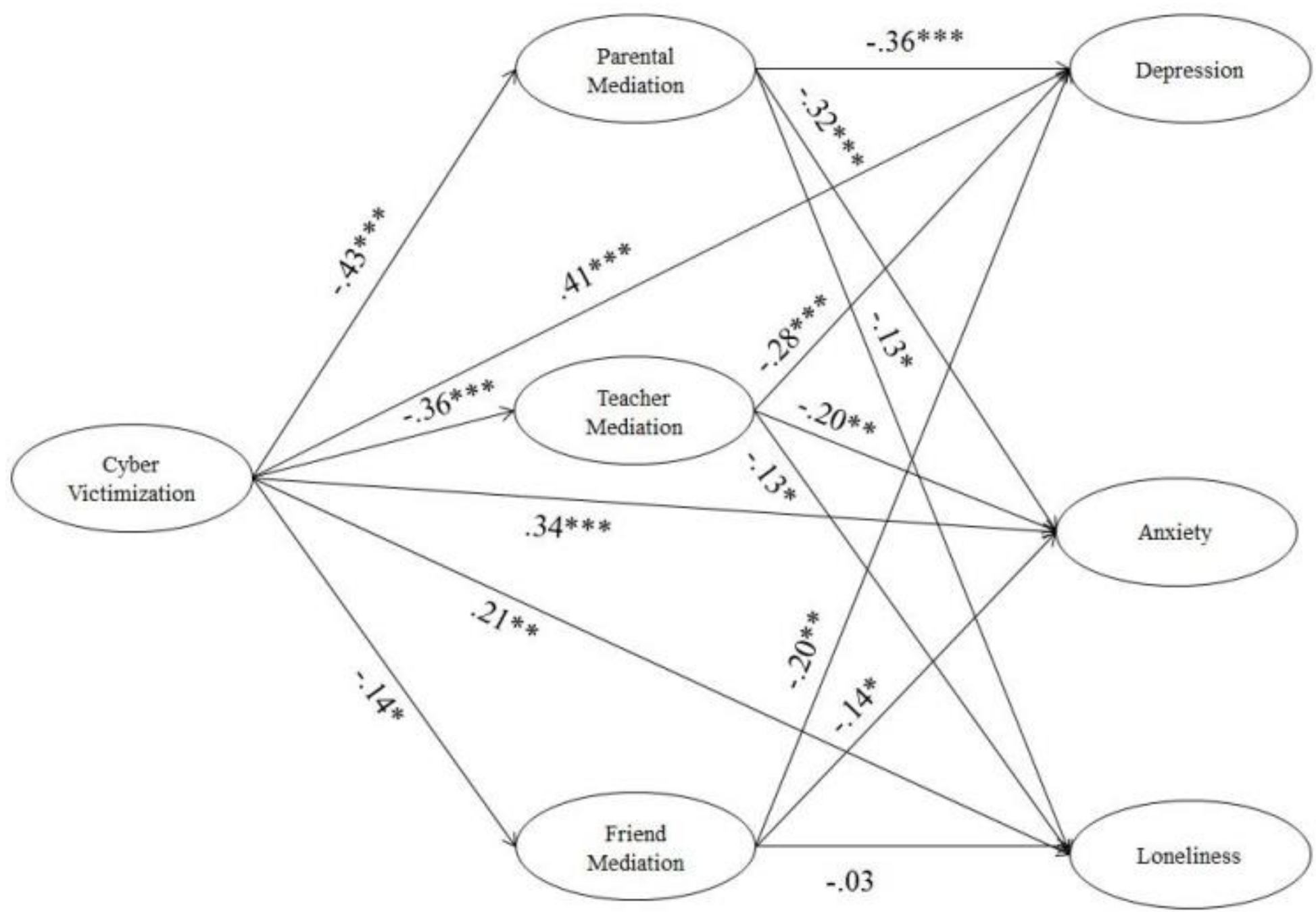

Figure 1. Structural regression model for the associations among Chinese adolescents' cyber victimization, technology mediation, and adjustment difficulties. To facilitate reading, face-to-face victimization as a covariate was not included nor were the moderation effects. Face-to-face victimization was related positively to cyber victimization $(\beta=.26, p<.001)$. The moderation of parental mediation and teacher mediation in the relationship between cyber victimization and depression (parental mediation: $\beta=.26, p$ $<.001$; teacher mediation: $\beta=.18, p<.01$ ) as well as cyber victimization and anxiety (parental mediation: $\beta=.19, p<.01$; teacher mediation: $\beta=.12, p<.05)$ were significant. The other moderation effects were not significant.

\section{Discussion}

This study investigated whether mediation by parents, teachers, and friends could reduce or buffer the relationships among cyber victimization and associated psychological adjustment difficulties (i.e., depression, anxiety, and loneliness). Results from this study and others contribute to a growing body of research suggesting that the mitigating effects of technology mediation on cyber victimization might be universal. Parental mediation was more common than mediation from teachers or friends for both Chinese and American adolescents, which is consistent with previous research concerning parental mediation (Dehue et al., 2008; Livingstone et al., 2011; Mesch, 2009; Navarrao et al., 2013). Chinese adolescents experienced more parental mediation than American adolescents. Differences were found concerning mediation by teachers and friends across the different countries. In particular, Chinese adolescents reported more teacher mediation than friend mediation, whereas American adolescents reported the opposite pattern. These findings are difficult to resolve based on the current research on cyberbullying, though research does reveal that teachers and peers are sources of adolescents' technology mediation (Calvete et al., 2010; Mishna et al., 2010; Šléglová \& Černá, 2011). 


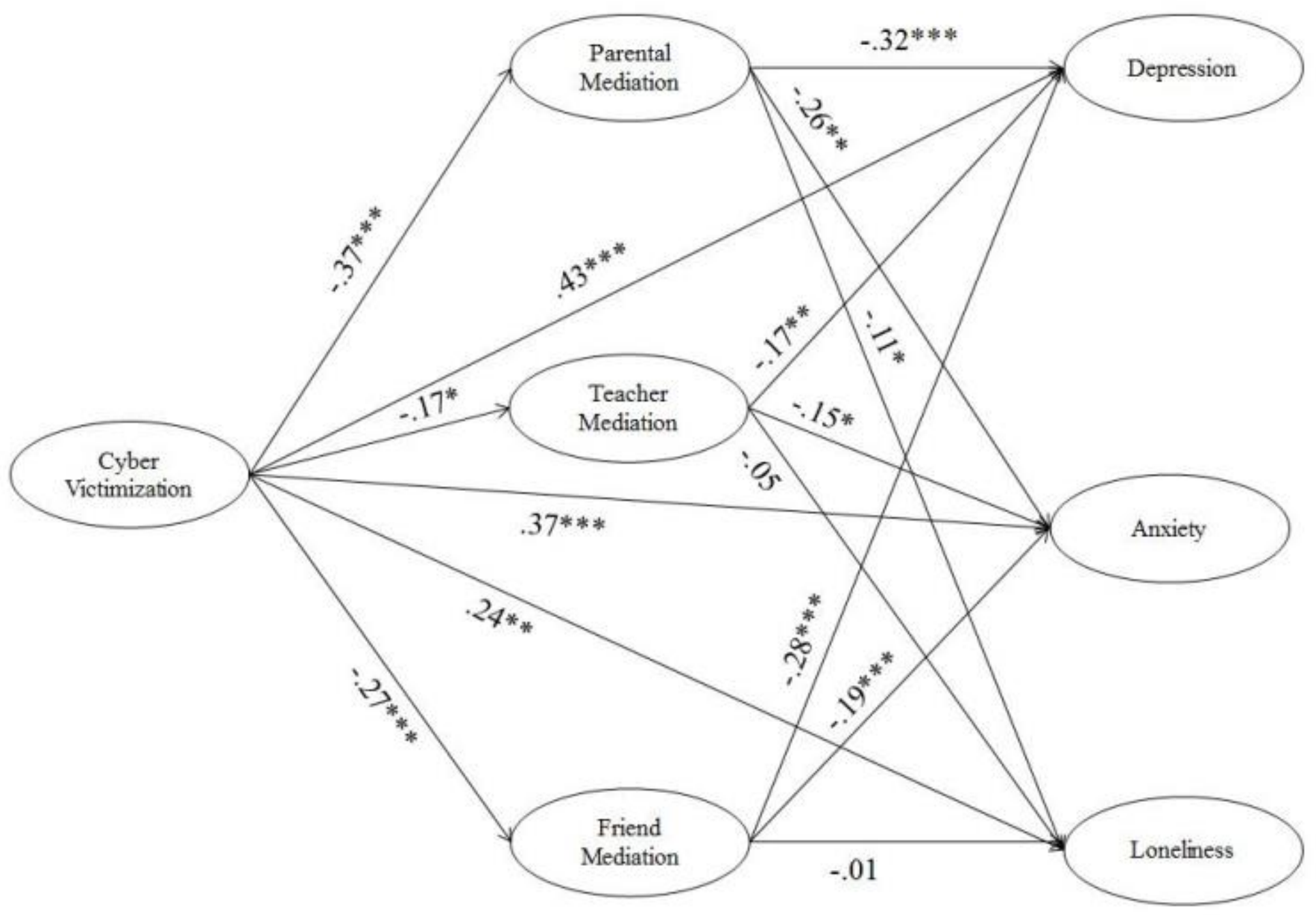

Figure 2. Structural regression model for the associations among American adolescents' cyber victimization, technology mediation, and adjustment difficulties. To facilitate reading, face-to-face victimization as a covariate was not included nor were the moderation effects. Face-to-face victimization was related positively to cyber victimization $(\beta=.32, p<.001)$. The moderation of parental mediation and friend mediation in the relationship between cyber victimization and depression (parental mediation: $\beta=.24, p<.001$; friend mediation: $\beta=.21, p<.01$ ) as well as cyber victimization and anxiety (parental mediation: $\beta=.23, p<.001$; friend mediation: $\beta=.14, p<.05)$ were significant. The other moderation effects were not significant.

In the broader literature on mediation, parents, teachers, and peers contribute differential levels of intervention and support, based on adolescents' country of origin. Most of this European research (Livingstone et al., 2011; Mesch, 2009; Šléglová \& Černá, 2011) shows that country of origin and the type of mitigating agent makes a difference to the degree to which adolescents' use of the internet is mediated. This mediation can be seen as a form of social support, particularly when adolescents discuss online problematic situations (Livingstone et al., 2011). Mediation might offer adolescents support and guidance in their technology usage, especially when they have technology-related problems or experience uncomfortable situations while using digital technologies. Support for technology mediation as a form of social support is apparent as research suggests that parental mediation, teacher mediation, and friend mediation reduce the risk of experiencing cyber victimization (Calvete et al., 2010; Mesch, 2009; Navarro et al., 2013; Šléglová \& Černá, 2011).

It is through the examination of technology mediation as a moderator in the relationships among cyber victimization and psychosocial adjustment difficulties that we are better able to understand the complexity of such associations. Finding that different mitigating agents moderate the associations between cyber victimization and psychosocial adjustment difficulties suggest that such mediation buffers against the negative effects of cyber victimization. More specifically, high levels of parental mediation reduced the negative relationship of cyber victimization to depression and anxiety, but not loneliness among Chinese 
and American adolescents. Such findings might be consistent with the literature as parental mediation reduces the risk of cyber victimization, but there is no research available on whether it also decreases the associated psychosocial adjustment difficulties (Mesch, 2009; Navarro et al., 2013). The results also revealed that when there were low levels of parental mediation the relationship between cyber victimization and depression as well as between cyber victimization and anxiety were stronger. The current research suggests that parental mediation serves an important role in buffering against the negative effects of cyber victimization.

There were some differences found concerning adolescents' country of origin. More specifically, the relationship of cyber victimization to depression and anxiety was more negative when Chinese adolescents reported high levels of teacher mediation. Like the findings for parental mediation, low levels of teacher mediation increased the positive relationship between these variables. Similar relationships were found for American adolescents, but for friend mediation instead of teacher mediation. Such findings indicate that teachers and friends serve different functions, depending on the country of origin, when it comes to reducing the impact of cyber victimization on adolescents' psychosocial adjustment difficulties. Research is lacking concerning the role of other mitigating agents in mediating adolescents' cyber victimization, which makes it difficult to connect the current study's findings with previous research. However, the differential moderation of mitigating agents for Chinese and American adolescents is supported by the broader literature on parenting in general. The early sections discussed how, in China, adolescents are socialized to respect their elders, which might indicate that teacher mediation would be more influential for reducing the psychosocial adjustment difficulties associated with cyber victimization (Ho, 1996; Yeh \& Bedford, 2004). In contrast, peer culture is strongly influential to American adolescents, and, consequently, friends become extremely important in their lives (Parker et al., 2006). Thus, friends might serve a more mitigating role in the risks associated with American adolescents' technology usage when compared to teachers.

The association between loneliness and cyber victimization was not moderated by parental mediation, teacher mediation, or friend mediation. The available literature does link cyber victimization to loneliness among adolescents (Brighi, Guarini, Melotti, Galli, \& Genta, 2012; Jackson \& Cohen, 2012). The present study did find relationships between these variables, except only for the correlational analyses. One possible explanation for parental mediation, teacher mediation, and friend mediation not moderating these relationships might be that loneliness is more resistant to change. More research should be conducted to follow-up on this proposal.

\section{Limitations and Future Directions}

Despite this study providing a valuable contribution to the literature on cultural differences in the mediation of adolescents' use of digital technology, there are some notable limitations and future directions that should be discussed to advance research in this area. The first way in which future studies could be enhanced is to examine the relationships investigated in this study through longitudinal research designs. Such designs will allow for a better understanding of the long-term implications of the mediation of adolescents' technology usage, and how this mediation may reduce cyber victimization and the associated psychological adjustment difficulties. Some mitigating agents may have more of an influence on these associations over time. Although friends are central to adolescents' lives, parents have a major role in mitigating the negative effects of cyber victimization as was indicated by the findings of this study. However, at younger ages, children's friends are important but not as important as they are in adolescence, and, therefore, friends might not have such a pronounced mitigating role in younger children's use of technology. Longitudinal designs would allow researchers to examine changes over time related to the shifts in the importance of core relationships in children's lives. Furthermore, this study utilized similar questionnaires for mediation among different mitigating agents. Although attempts were made to create some unique items for the questionnaire, some of the differences among parents, peers, and teachers may reflect the particular questions asked about mediation in this survey where the emphasis is on the agent offering advice. Therefore, in the future additional attention should be given to understanding whether different meditational strategies are engaged in by parents, peers, and teachers. For example, the EU Kids Online study found that peers offer less advice on eSafety (Livingstone et al., 2011), yet children turned to their peers more than parents or teachers when online problems emerged. This research should also involve qualitative methods to investigate and conceptualize these different types of meditational practices, which in turn may depend on the mitigating agents' relationship to the adolescent.

Another factor that should be examined is the quality of the relationship with the mitigating agent as well as parenting styles. Relationship quality and parenting styles might make some adolescents more or less susceptible to being influenced by attempts to mediate their use of technologies. For example, 
authoritative parenting styles and better relationship quality with parents could contribute to parental mediation decreasing the chances that the cyber victimization of adolescents will lead to associated psychological adjustment difficulties. Similar patterns concerning relationship quality might be found when it comes to other mitigating agents, like teachers and friends. A final future direction would be to examine different mediational strategies. For instance, Arrizabalaga-Crespo and colleagues (2010) described four different mediational strategies, including restrictive, shared (i.e., co-viewing), instructive or evaluative mediation, and unfocused mediation. These mediational strategies might change the buffering effect that technology mediation has on cyber victimization and the associated psychosocial adjustment difficulties.

\section{Conclusions}

The present study is one of the few to compare cross-cultural differences in technology mediation by different mitigating agents, including parents, teachers, and friends. It is also one of a handful of studies to examine the buffering effects of technology mediation on cyber victimization and whether this buffering effect also reduces the relationship between cyber victimization and adolescents' adjustment difficulties. Such a focus provides an important direction for the field as teacher mediation is more pertinent to reducing the negative impacts of cyber victimization among Chinese adolescents, while friend mediation matters more for American adolescents. Furthermore, high and low levels of parent mediation moderated the relationship between cyber victimization and adolescents' experience of depression and anxiety. These findings further indicate the importance of a multi-prong solution focused on raising awareness about the potential for the mediation of children's use of digital technologies to reduce the psychosocial adjustment difficulties associated with cyber victimization among adolescents in China and the United States.

\section{Acknowledgements}

This work was supported by the project "Employment of Best Young Scientists for International Cooperation Empowerment" (CZ.1.07/2.3.00/30.0037) co-financed from European Social Fund and the state budget of the Czech Republic.

\section{References}

Abelman, R. (2006). Fighting the war on indecency: Mediating TV, Internet, and videogame usage among achieving and underachieving gifted children. Roeper Review: A Journal of Gifted Education, 29, 100-112. http://dx.doi.org/10.1080/02783190709554393

Arrizabalaga-Crespo, C., Aierbe-Barandiaran, A., \& Medrano-Samaniego, C. (2010). Internet uses and parental mediation in adolescents with ADHD. Revista Latina de Comunicación, 65, 561-571.

Bavelier, D., Green, C. S., \& Dye, M. W. G. (2010). Children, wired: For better and for worse. Neuron, 67, 692-701. http://dx.doi.org/10.1016/j.neuron.2010.08.035

Bauman, S., Toomey, R. B., \& Walker, J. L. (2013). Associations among bullying, cyberbullying, and suicide in high school students. Journal of Adolescence, 36, 341-350.

http://dx.doi.org/10.1016/j.adolescence.2012.12.001

Blackwell, C. K., Lauricelli, A. R., \& Wartella, E. (2014). Factors influencing digital technology use in early childhood education. Computers \& Education, 77, 82-90.

http://dx.doi.org/10.1016/j.compedu.2014.04.013

Brighi, A., Guarini, A., Melotti, G., Galli, S., \& Genta, M. L. (2012). Predictors of victimisation across direct bullying, indirect bullying and cyberbullying. Emotional \& Behavioural Difficulties, 17, 375-388.

http://dx.doi.org/10.1080/13632752.2012.704684

Calvette, E., Orue, I., Estévez, A., Villardón, L., \& Padilla, P. (2010). Cyberbullying in adolescents:

Modalities and aggressors' profile. Computers in Human Behavior, 26, 1128-1135.

http://dx.doi.org/10.1016/j.chb.2010.03.017

Campbell, M., Speras, B., Slee, P., Butler, D., \& Kift, S. (2012). Victims' perceptions of traditional and cyberbullying and the psychosocial correlates of their victimization. Emotional and Behavioural Difficulties, 17, 389-401. http://dx.doi.org/10.1080/13632752.2012.704316 
Chang, F., Chiu, C., Miao, N., Chen, P., Lee, C., Chiang, J., \& Pan, Y. (2014). The relationship between parental mediation and Internet addiction among adolescents, and the association with cyberbullying and depression. Comprehensive Psychiatry. Advance online publication.

http://dx.doi.org/10.1016/j.comppsych.2014.11.013

Dehue, F., Bolman, C., Völlink, T. (2008). Cyberbullying: Youngsters' experiences and parental perception. CyberPsychology \& Behavior, 11, 217-223. http://dx.doi.org/10.1089/cpb.2007.0008

Dooley, J. J., Pyzalski, J., \& Cross, D. (2009). Cyberbullying versus face-to-face bullying: A theoretical and conceptual review. Journal of Psychology, 217(4), 182-188. http://dx.doi.org/10.1027/0044-

3409.217.4.182

Dumont, M., \& Provost, M. A. (1999). Resilience in adolescents: Protective role of social support, coping strategies, self-esteem, and social activities on experience of stress and depression. Journal of Youth \& Adolescence, 28, 343-363. http://dx.doi.org/10.1023/A:1021637011732

Edwards, C. P., Rosario de Guzman, M., Brown, J., \& Kumru, A. (2006). Children's social behaviors and peer interactions in diverse cultures. In X. Chen, D. French, \& B. Schneider (Eds.), Peer Relationships in Cultural Context (pp. 23-51). Cambridge, MA: Cambridge University Press.

Gámez-Guadix, M., Orue, I., Smith, P. K., \& Calvete, E. (2013). Longitudinal and reciprocal relations of cyberbullying with depression, substance use, and problematic Internet use among adolescents. Journal of Adolescent Health, 53, 446-452. http://dx.doi.org/10.1016/j.jadohealth.2013.03.030

Grigg, D. W. (2010). Cyber-aggression: Definition and concept of cyberbullying. Australian Journal of Guidance and Counselling, 20(2), 143-156. http://dx.doi.org/10.1375/ajgc.20.2.143

Helsper, E. J., Kalmus, V., Hasebrink, W., Sagvari, B., \& De Haan, J. (2013). Country classification: Opportunities, risks, harm and parental mediation. London: EU Kids Online.

Ho, D. Y. F. (1981). Traditional patterns of socialization in Chinese society. Acta Psychologica Taiwanica, 23(2), 81-95.

Huang, Y., \& Chou, C. (2010). An analysis of multiple factors of cyberbullying among junior high school students in Taiwan. Computers in Human Behavior, 26, 1581-1590.

http://dx.doi.org/10.1016/j.chb.2010.06.005

Jackson, C. L., \& Cohen, R. (2012). Childhood victimization: Modeling the relation between classroom victimization, cyber victimization, and psychosocial functioning. Psychology of Popular Media Culture, 1 , 254-269. http://dx.doi.org/10.1037/a0029482

Kim, J., Suh, W., Kim, S., \& Gopalan, H. (2012). Coping strategies to manage acculturative stress: Meaningful activity participation, social support, and positive emotion among Korean immigrant adolescents in the USA. International Journal of Qualitative Studies on Health and Well-Being, 7, 1-10. http://dx.doi.org/10.3402/qhw.v7i0.18870

Kowalski, R. M., \& Limber, S. P. (2013). Psychological, physical, and academic correlates of cyberbullying and traditional bullying. Journal of Adolescent Health, 53, S13-S20.

http://dx.doi.org/10.1016/j.jadohealth.2012.09.018

Landstedt, E., \& Persson, S. (2014). Bullying, cyberbullying, and mental health in young people. Scandinavian Journal of Public Health, 42, 393-399. http://dx.doi.org/10.1177/1403494814525004

Lee, V. C., \& Thomas, J. M. (2011). Integrating physical activity data technologies into elementary school classrooms. Educational Technology Research and Development, 59, 865-884.

http://dx.doi.org/10.1007/s11423-011-9210-9

Lepičnik-Vodopivec, J., \& Samec, P. (2012). Advantages and disadvantages of information-communication technology usage for four-year-old children, and the consequences of its usage for the childrens'

development. International Journal of Humanities and Social Science, 2(3), 54-58. 
Li, Q. (2006). Cyberbullying in schools: A research of gender differences. School Psychology International, 27, 157-170. http://dx.doi.org/10.1177/0143034306064547

Livingstone, S., Haddon, L., Görzig , A., \& Ólafsson, K. (2011). Risks and safety on the Internet: The perspective of European children. LSE, London, UK: EU Kids Online.

Livingstone, S., \& Helsper, E. J. (2008). Parental mediation of children's Internet use. Journal of Broadcasting \& Electronic Media, 52, 581-599. http://dx.doi.org/10.1080/08838150802437396

Lwin, M. O., Stanaland, A., \& Miyazaki, A. D. (2008). Protecting children's privacy online: How parental mediation strategies affect website safeguard effectiveness. Journal of Retailing, 84, 205-217. http://dx.doi.org/10.1016/j.jretai.2008.04.004

Martínez de Morentin, J., Cortés, A., Medrano, C., \& Apodaca, P. (2014). Internet use and parental mediation: A cross-cultural study. Computers \& Education, 70, 212-221.

http://dx.doi.org/10.1016/j.compedu.2013.07.036

Mascheroni, G., Jorge, A., \& Farrugia, L. (2014). Media representations and children's discourses on online risks: Findings from qualitative research in nine European countries. Cyberpsychology: Journal of Psychosocial Research on Cyberspace, 8(2), article 2. http://dx.doi.org/10.5817/CP2014-2-2

Mesch, G. S. (2009). Parental mediation, online activities, and cyberbullying. CyberPsychology \& Behavior, 12(4), 387-393. http://dx.doi.org/10.1089/cpb.2009.0068

Mishna, F., Cook, C., Gadalla, T., Daciu, J., \& Solomon, S. (2010). Cyber bullying behaviors among middle and high school students. American Journal of Orthopsychiatry, 80, 362-374.

http://dx.doi.org/10.1111/j.1939-0025.2010.01040.x

Mitchell, K., Ybarra, M., \& Finkelhor, D. (2007). The relative importance of online victimization in understanding depression, delinquency \& substance use. Child Maltreatment, 12, 314-324.

http://dx.doi.org/10.1177/1077559507305996

Mordkowitz, E. R., \& Ginsburg, H. P. (1987). Early academic socialization of successful Asian American college students. Quarterly Newsletter of the Laboratory of Comparative Human Cognitive, 9(2), 85-91.

Navarro, R., Serna, C., Martínez, V., Ruiz-Oliva, R. (2013). The role of Internet use and parental mediation on cyberbullying victimization among Spanish children from rural public schools. European Journal of Psychology of Education, 28, 725-745. http://dx.doi.org/10.1007/s10212-012-0137-2

Nijs, L., \& Leman, M. (2014). Interactive technologies in the instrumental music classroom: A longitudinal study with the Music Paint Machine. Computers \& Education, 73, 40-59.

http://dx.doi.org/10.1016/j.compedu.2013.11.008

Nikken, P., \& Jansz, J. (2006). Parental mediation of children's videogame playing: A comparison of the reports by parents and children. Learning, Media and Technology, 31, 181-202.

http://dx.doi.org/10.1080/17439880600756803

Olenik-Shemesh, D., Heiman, T., \& Eden, S. (2012). Cyberbullying victimisation in adolescence:

Relationships with loneliness and depressive mood. Emotional \& Behavioural Difficulties, 17, 361-374.

http://dx.doi.org/10.1080/13632752.2012.704227

Parker, J. G., Rubin, K. H., Erath, S. A., Wojslawowicz, J. C., \& Buskirk, A. A. (2006). Peer relationships, child development, and adjustment: A developmental psychopathology perspective. In D. Cicchetti \& D. J. Cohen (Eds.), Developmental Psychopathology, Vol 1: Theory and Method (pp. 419-493). Hoboken, NJ: John Wiley \& Sons.

Rivers, I., \& Noret, N. (2010). 'I h8 u': Findings from a five-year study of text and e-mail bullying. British Educational Research Journal, 36, 543-571. http://dx.doi.org/10.1080/01411920903071918 
Rosen, L. D., Whaling, K., Carrier, L. M., Cheever, N. A., \& Rokkum, J. (2013). The media and technology usage and attitude scales: An empirical investigation. Computers in Human Behavior, 29, 2501-2511. http://dx.doi.org/10.1016/j.chb.2013.06.006

Rothbaum, F., Morelli, G., Pott, M. \& Liu-Constant, Y. (2000). Immigrant-Chinese and Euro-American parents' physical closeness with young children: Themes of family relatedness. Journal of Family Psychology, 14, 334-348. http://dx.doi.org/10.1037/0893-3200.14.3.334

Russell, D. (1996). UCLA loneliness scale (Version 3): Reliability, validity, and factor structure. Journal of Personality Assessment, 66, 20-40. http://dx.doi.org/10.1207/s15327752jpa6601_2

Schenk, A. M., Fremouw, W. J., \& Keelan, C. M. (2013). Characteristics of college cyberbullies. Computers in Human Behavior, 29, 2320-2327. http://dx.doi.org/10.1016/j.chb.2013.05.013

Šléglová, V., \& Černá, A. (2011). Cyberbullying in adolescent victims: Perception and coping. Cyberpsychology: Journal of Psychosocial Research on Cyberspace, 5(2), article 4. Retrieved from: http://www.cyberpsychology.eu/view.php?cisloclanku=2011121901\&article=4

Smith, P. K., Mahdavi, J., Carvalho, M., Fisher, S., Russell, S., \& Tippett, N. (2008). Cyberbullying: Its nature and impact in secondary school pupils. Journal of Child Psychology and Psychiatry, 49, 376-385. http://dx.doi.org/ 10.1111/j.1469-7610.2007.01846.x

Thorsteinsson, E., Ryan, S., \& Sveinbjornsdottir, S. (2013). The mediating effects of social support and coping on the stress-depression relationship in rural and urban adolescents. Open Journal of Depression, 2(1), 1-6. http://dx.doi.org/10.4236/ojd.2013.21001

Van Den Eijnden, R., Meerkerk, G., Vermulst, A., Spijkerman, R., \& Engels, R. C. M. E. (2008). Online communication, compulsive Internet use, and psychosocial well-being among adolescents: A longitudinal study. Developmental Psychology, 44, 655-665. http://dx.doi.org/10.1037/0012-1649.44.3.655

Wang, W., \& Leichtman, M. D. (2000). Same beginnings, different stories: A comparison of American and Chinese children's narratives. Child Development, 71, 1329-1346. http://dx.doi.org/10.1111/1467-

8624.00231

Wright, M. F. (2014). Longitudinal investigation of the associations between adolescents' popularity and cyber social behaviors. Journal of School Violence, 13, 291-314.

http://dx.doi.org/10.1080/15388220.2013.849201

Wright, M. F., Li, Y., Shi, J. (2014). Chinese adolescents' social status goals: Associations with beahviors and attributions for relational aggression. Youth \& Society, 46, 566-588.

http://dx.doi.org/10.1177/0044118x12448800

Yao, E. (1985). A comparison of family characteristics of Asian-American and Anglo-American high achievers. International Journal of Comparative Sociology, 26(34), 198-208.

http://dx.doi.org/10.1163/156854285x00051

Yeh, K. H., \& Bedford, O. (2004). Filial piety and parent-child conflict. International Journal of Psychology, 39, 132-144. http://dx.doi.org/10.1080/00207590344000312

\section{Correspondence to:}

Michelle F. Wright

Faculty of Social Studies

Jostova 10

Brno

60200

Czech Republic

Email: michelle.wright(at)mail.muni.cz 


\begin{abstract}
About author
Michelle F. Wright is a postdoctoral research fellow at Masaryk University in the Czech Republic. Her major research interests include the contextual influences, particularly cultural and familial, on adolescents' social behaviors, and their pursuit and achievement of peer status. For the past several years, she has studied victimization and aggression through electronic technologies among children, adolescents, and young adults.
\end{abstract}

